\title{
Structural Proteins of Simian Virus 40
}

\author{
STANLEY BARBAN AND RONALD S. GOOR \\ Laboratory of Biology of Viruses, National Institute of Allergy and Infectious Diseases, National Institutes of \\ Health, Bethesda, Maryland 20014
}

Received for publication 19 October 1970

\begin{abstract}
Sodium dodecyl sulfate acrylamide gel electrophoresis of the solubilized proteins from purified simian virus 40 (SV40) virions revealed two major and two minor structural polypeptide components. The major components which comprise over $75 \%$ of the total virion were shown to be the capsid proteins by immunological and isoelectric focusing fractionation analysis. These two polypeptides have estimated molecular weights of 45,000 daltons as determined by gel electrophoresis. One of the two minor components was identified as the nucleocapsid protein and has an approximate molecular weight of 16,000 . The other unidentified minor component has an average molecular weight of 29,000 .
\end{abstract}

The small oncogenic simian virus 40 (SV40) which has a deoxyribonucleic acid (DNA) content of approximately $2.3 \times 10^{6}$ to $3.0 \times 10^{6}$ daltons $(1,4)$ can code for only 7 to 10 proteins of average molecular weight. Those proteins that are not considered to be part of the virus particle (nonstructural) include the tumor (T), transplantation, and surface antigens $(3,6,19,20)$ and certain enzymes $(9,10)$. Published studies describing SV40 structural proteins differ both in the number of polypeptide subunits and their molecular weights. Anderer et al. (1), employing membrane electrophoresis, sedimentation and diffusion analyses, reported that SV40 virions contained three different polypeptide chains with an average molecular weight of 16,350. Recently, Girard et al. (5) employing polyacrylamide gel electrophoresis described six different polypeptide chains in SV40 virions with molecular weights ranging from 45,000 to 10,000 .

In this report we analyzed the structural proteins of SV40 by polyacrylamide gel electrophoresis and isoelectric focusing procedures. Data on the molecular weights, location in the virion, and some of the immunological properties of the viral structural proteins are presented.

\section{MATERIALS AND METHODS}

Cell cultures. Primary African green monkey kidney (AGMK) cells and Vero cells, a continuous cell line isolated from AGMK, were grown in 32-oz prescription bottles or in 1-gal.-size roller bottles in Eagle's no. 2 minimal essential medium supplemented with 5 to $10 \%$ fetal calf serum.

Virus infection. The virus was the small plaque strain of SV40 kindly supplied by Harvey L. Ozer. When the cells became confluent, they were infected with SV40 virus at a multiplicity of 0.1 to 5 plaqueforming units (PFU) per cell. The infected cells were harvested 6 to 8 days after infection, and the virus was isolated from the supernatant fluids and cells after three cycles of freeze-thawing. An initial concentration of the virus from the growth medium was performed in an Amicon ultrafiltration unit.

Preparation of radioactive virus. Confluent monolayer cultures were infected with SV40 virus at 0.1 to 5 PFU per cell. After a 2-hr adsorption period, fresh medium containing $2 \%$ fetal calf serum was added. Fresh medium containing $1 \%$ dialyzed fetal calf serum, one-fifth the usual concentration of aminoacids, and 0.1 to $1 \mu \mathrm{Ci}$ of reconstituted ${ }^{3} \mathrm{H}$ or ${ }^{14} \mathrm{C}$ labeled protein hydrolysate or single amino acids per $\mathrm{ml}$ (Schwarz Bio-Research, Inc. or New England Nuclear Corp. Boston, Mass.) were added 24 to $48 \mathrm{hr}$ after infection. The cells were incubated at $37 \mathrm{C}$ for an additional 3 to 5 days, and the virus was then harvested and purified.

Virus purification. The concentrated virus suspension was purified by zone sedimentation onto a $\mathrm{CsCl}$ cushion $\left(1.4 \mathrm{~g} / \mathrm{cm}^{3}\right)$ followed by two cycles of $\mathrm{CsCl}$ $\left(1.34 \mathrm{~g} / \mathrm{cm}^{3}\right)$ equilibrium density centrifugation.

Preparation of subviral particles. Purified SV40 virus particles banding at a density of $1.33 \mathrm{~g} / \mathrm{cm}^{3}$ were degraded by exposure to buffer $(p \mathrm{H} 10.5)$ as described by Anderer et al. (2). The capsid protein component was separated from a core protein-DNA complex by 5 to $20 \%$ sucrose gradient centrifugation in a SW41 rotor for $4 \mathrm{hr}$ at $40,000 \mathrm{rev} / \mathrm{min}$.

Solubilization of virions and subviral particles. Purified virus suspended in $0.01 \mathrm{M}$ tris(hydroxymethyl)aminomethane (Tris, $p \mathrm{H} \mathrm{7.2)}, 0.15 \mathrm{M} \mathrm{NaCl}$ buffer at a protein concentration of 150 to $500 \mu \mathrm{g} / \mathrm{ml}$ was degraded by treatment with $2 \%$ sodium dodecyl sulfate (SDS), 1\% 2-mercaptoethanol (ME), and heating for 1 min at $100 \mathrm{C}(13)$. In some experiments virus or subunits were dissociated by $8 \mathrm{~m}$ urea, reduced with ME, and the thiol groups carboxymethylated with iodacetamide by a modification of the method of Hirs (7). 
Polyacrylamide gel electrophoresis. Gels were made by the method of Summers and Maizel (18) and consisted of $10 \%$ acrylamide, $0.26 \% \mathrm{C}, N^{1}$-bis-methylene acrylamide, $0.1 \%$ SDS, and $0.1 \mathrm{M}$ sodium phosphate buffer $(p H$ 7.2). Samples of viral protein (50 to 200 $\mu \mathrm{g}$ ) in 0.05 - to $0.20-\mathrm{ml}$ buffer containing $10 \%$ sucrose were electrophoresed at 3 to 4 ma per gel for 15 to 16 hr at $20 \mathrm{C}$. After electrophoresis, gels were fixed in $10 \%$ trichloracetic acid, stained with $0.1 \%$ Coomassie blue in $10 \%$ trichloroacetic acid, and destained with $7.5 \%$ acetic acid. Gels containing radioactive proteins were frozen, sliced, and solubilized with $30 \% \mathrm{H}_{2} \mathrm{O}_{2}$ by the method of Moss (14).

Isoelectric focusing fractionation. This was carried out in a linear sucrose density gradient (from 50 to $1 \%$ ) with an LKB model 8101 electrofocusing jacketed column as described by Vesterberg and Svensson (22). The concentration of the carrier ampholyte was $1 \%$ covering a $p \mathrm{H}$ range of between 3 and 10 . The sample was introduced in the middle portion of the column. A current of $300 \mathrm{v}$ was applied for 40 to $48 \mathrm{hr}$.

Preparation of immune sera. Antiviral antiserum was prepared in rabbits from highly purified SDS degraded virus particles and viral subunit antigens as described by Horowitz and Scharff (8).

Immunodiffusion. The double diffusion technique of Ouchterlony was carried out on microscope slides as described by Salzman and Moss (15). In addition to the usual procedures, immunodiffusion assays were carried out after electrophoretic separation in SDS polyacrylamide gels. Gel slices of $1.3 \mathrm{~mm}$ were cut from frozen gels corresponding to stained protein bands in duplicate gels, frozen, and thawed twice in phosphate-buffered saline to elute the proteins, and the extracts were placed in the wells of the immunodiffusion slides. Immunological reactivity was observed by the development of immunoprecipitin lines after incubation with immune sera or with $\gamma$ globulin fractions of the sera.

Protein analysis. The procedure of Lowry et al. was employed to measure protein (12).

\section{RESULTS}

Polyacrylamide-gel electrophoresis of viral proteins. Purified preparations of small plaque SV40 virus were dissociated by treatment with SDS and ME as described. In some experiments, virions were dissociated with $8 \mathrm{~m}$ urea and the reduced sulfhydryl groups were carboxymetholated. The staining pattern (Fig. 1) showed two major bands, and three to four minor bands. Minor bands at the top of gel were observed only when large amounts of viral protein ( 200 to $300 \mu \mathrm{g}$ ) were employed. Their absence in many preparations led us to conclude that they represent aggregates. The staining patterns were reproducibly observed in many experiments with several different preparations of purified virus with the exception that the two major stained bands frequently were not well separated.

SV40 virions labeled with ${ }^{3} \mathrm{H}$-or ${ }^{14} \mathrm{C}$-amino acids were also analyzed; the radioactive pattern compared with the stained pattern is shown in in Fig. 2. The relative proportion of the total radioactivity in each of the peaks was: I and II, $80 \%$; III, $7 \%$; IV, 7 to $9 \%$; and $4 \%$ in the slowly migrating band at the top of gel. Approximately 85 to $95 \%$ of the applied radioactivity could be recovered from the gels.

The molecular weights of the viral proteins were determined by the method of Shapiro et al. (17) by comparing their electrophoretic mobilities with the migration of a series of proteins of known molecular weights. As shown in Fig. 3, the major protein components I and II, III, and IV have estimated molecular weights of approximately 45,000 (I, II), 29,000 (III), and 16,000 (IV) daltons.

To relate and characterize the proteins sep-

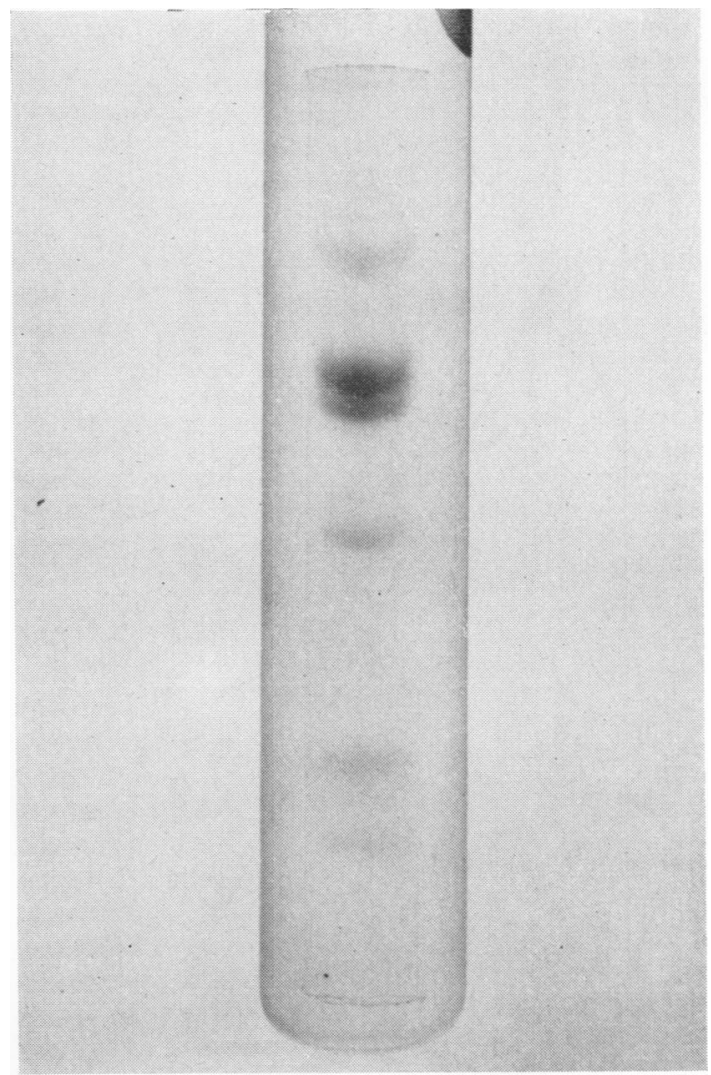

FIG. 1. Analytical polyacrylamide-gel electrophorograms of the dissociated proteins of SV40. Purified virus was dissociated and applied to $10 \%$ sodium dodecyl sulfate gels. Electrophoresis was for $5 \mathrm{hr}$ at $4 \mathrm{ma}$ per gel. After electrophoresis, gels were fixed in $10 \%$ trichloroacetic acid, stained with $0.1 \%$ Coomassie blue, and destained with $7.5 \%$ acetic acid. The anode is at the bottom of the gel. The length of gel was $7.5 \mathrm{~cm}$. 


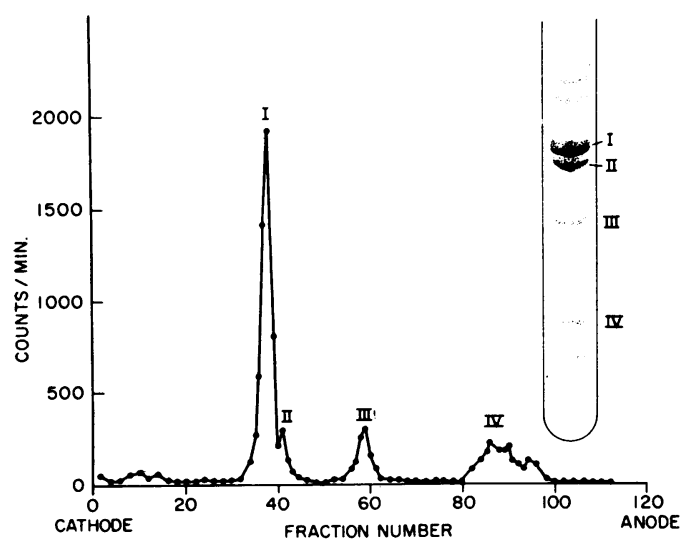

FIG. 2. Electrophoresis of $S V 40$ virion polypeptides labeled with ${ }^{3} \mathrm{H}$-lysine on a $10 \%$ polyacrylamide gel. Migration was from the origin at the left. Electrophoresis was for $15 \mathrm{hr}$ at $3 \mathrm{ma}$ per tube. Length of gel was 10 by $0.6 \mathrm{~cm}$.

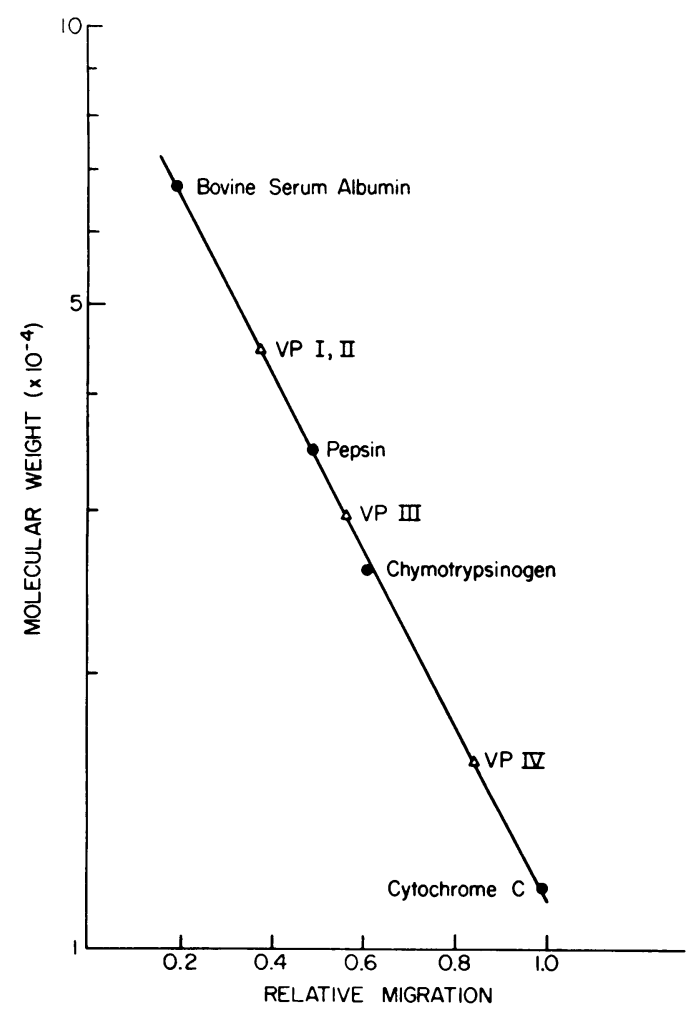

FIG. 3. Estimation of molecular weights of SV40 proteins. Electrophoretic migration of each protein, relative to the migration of cytochrome $c$, was plotted in parallel with reference proteins. $V P=$ virus polypeptide. arated by gel electrophoresis to the structural components of the virion, it was necessary to mildly degrade the virus particle. Anderer et al. have shown that SV40 virions can be disaggregated by exposure to a buffer $(p \mathrm{H} 10.5)$ of low ionic strength, and the degraded components can be separated by sucrose density gradient centrifugation into two fractions (Fig. 4). The fastest sedimenting peak (I) with 35 to $40 S$ value was identified as the nucleocapsid-DNA complex by labeling the DNA with ${ }^{14} \mathrm{C}$-thymidine. Radioactivity was found only in this peak (I). It contains viral DNA together with a limited amount of protein. The second major peak (II) has an $S$ value between 2.5 and 5.0 and is associated with the viral capsid protein as determined immunologically. When the concentrated protein obtained from capsid peak (II) of the alkaline sucrose density gradients was dissociated with SDS and ME and analyzed in SDS polyacrylamide gels, the results are as shown in Fig. 5. The capsid proteins appear to contain two polypeptide components. The electrophoretic characteristic of ${ }^{14} \mathrm{C}$-labeled capsid protein dissociated with SDS and analyzed in SDS gels is shown in Fig. 6a. Figure 6b shows the electrophoretic gel pattern of isolated nucleocapsid protein obtained from sucrose density gradient sedimentation of alkali dissociated

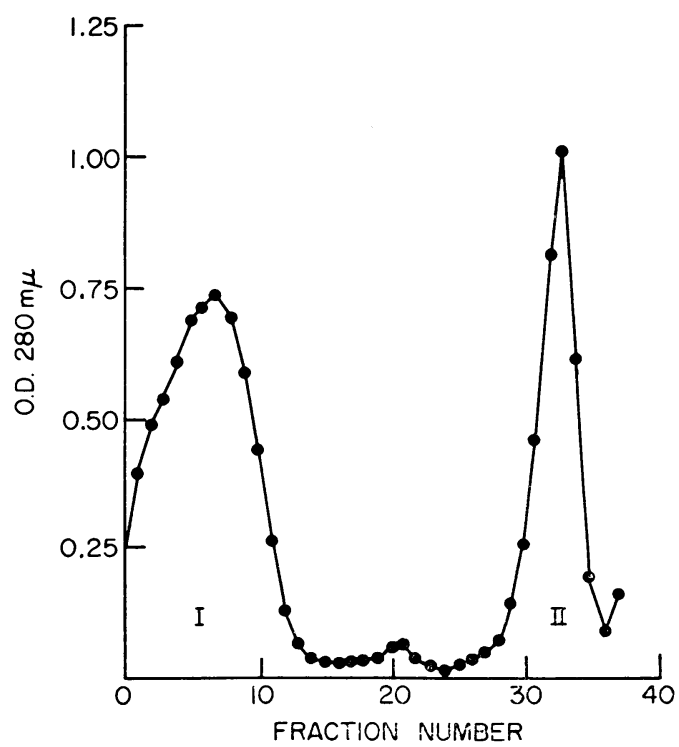

FIG. 4. Sucrose gradient analysis of SV40 treated with $\mathrm{pH} 10.5$ buffer at $5 \mathrm{C}$ for 18 to $20 \mathrm{hr}$. The dissociated virus was separated on a 5 to $20 \%(w / v)$ sucrose gradient in a pH 9.0 buffer and centrifuged at 39,000 rev/min for $4 \mathrm{hr}$ in a SW41 rotor at $5 \mathrm{C}$. Sedimentation was toward the left. 
virions. It appears to be heterogenous. To date, it has not been possible to determine if it contains more than one polypeptide chain because of the small amount of radioactivity recovered from preparative sucrose density gradient in this experiment.

Isoelectric focusing of SV40 capsid protein. To resolve the question of whether the capsid component is composed of one or more polypeptides, use was made of the electrofocusing technique of Vesterberg and Svensson (22). The results of this study are presented in Fig. 7. When capsid component isolated from alkaline dissociated SV 40 by sucrose density gradient sedimentation was fractionated by the electrofocusing method, two components were separated with isoelectric optima of $p \mathrm{H} 6.4$ and 5.5. Recovery of applied radioactivity from the column was generally from

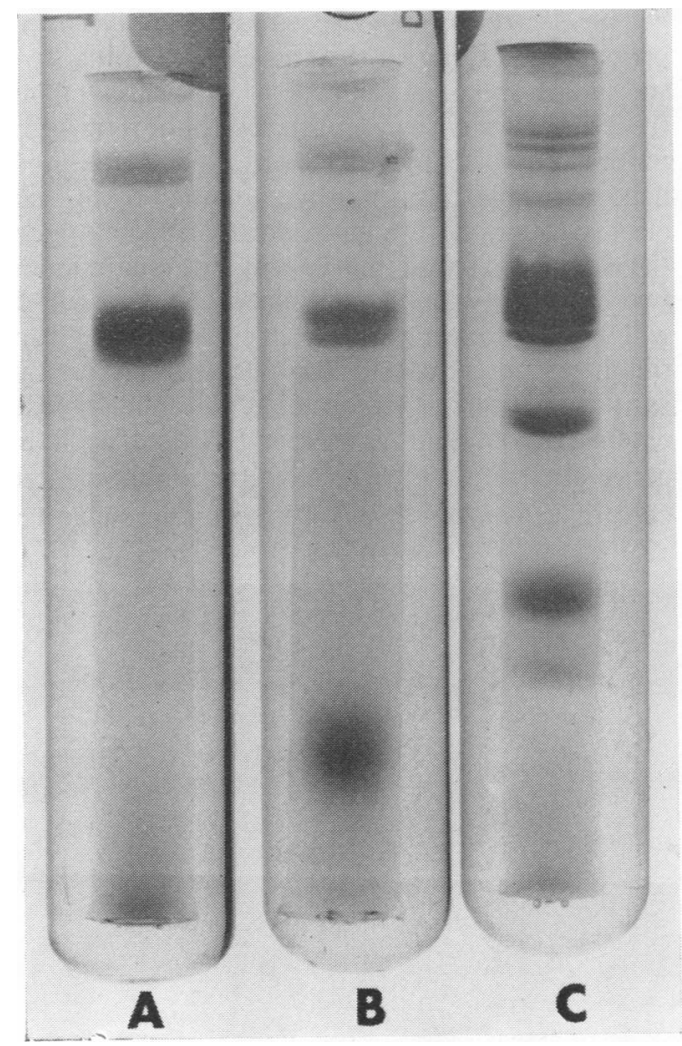

FIG. 5. Analytical polyacrylamide gel electropherograms of dissociated capsid proteins of SV40 and whole SV4O virions. (A) Capsids dissociated with sodium dodecyl sulfate (SDS); (B) SV40 capsids, dissociated with $8 . y$ urea. The bottom band in $B$ is a protein standard marker, cytochrome $c$. (C) Whole SV40 virions, SDS dissociated.

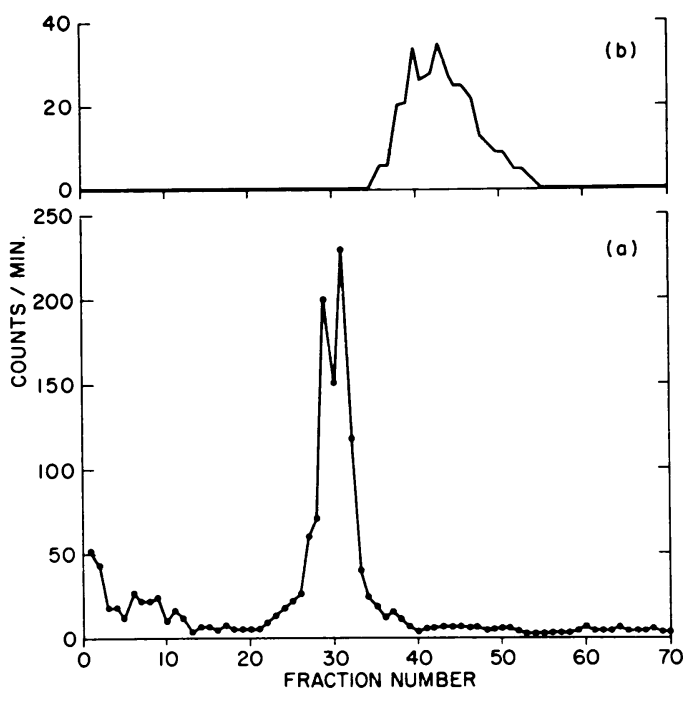

FIG. 6. Electrophoretic pattern of polypeptide composition of SV40 capsids and nucleocapsid protein. Capsids and nucleocapsid fractions were separated from alkaline dissociated SV4O virions by sucrose density gradient sedimentation. (a) Combined capsid component from a sucrose density gradient was dialyzed and dissociated with sodium dodecyl sulfate and 2mercaptoethanol and analyzed by gel electrophoresis. (b) Polypeptide pattern of the nucleocapsid component separated by sucrose density gradients is shown in the top panel.

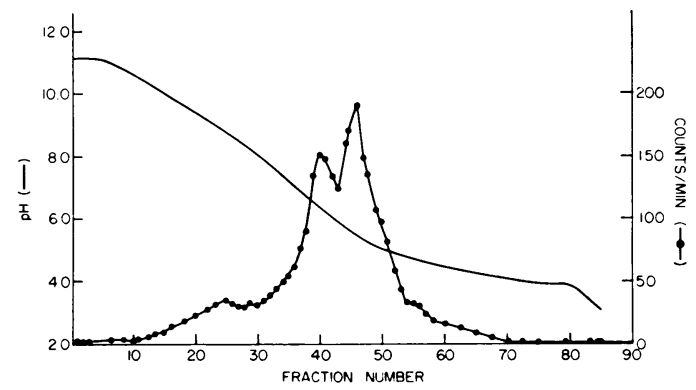

FIG. 7. Separation of SV40 capsid polypeptides by electrofocusing. The sucrose gradient contained $1 \%$ ampholytes ( $\mathrm{pH}$ range 3 to 10 ) and $8 . \mathrm{M}$ urea. SV40 capsid component was dissociated in 8 . 1 urea and $1 \%$ 2-mercaptoethanol and electrofocused for $42 \mathrm{hr}$ at a potential of 300 volts at 25 C. Fractions of $1 \mathrm{ml}$ were collected and assayed for $\mathrm{pH}$ and radioactivity.

30 to $35 \%$, probably due to the binding effects of the ampholine carrier.

Immunological analysis. The immunological reactivity of the solubilized whole SV40 proteins was assayed by the Ouchterlony double diffusion technique. The proteins formed a minimum of 
three distinct precipitin lines (Fig. 8a). In addition, the immunodiffusion method was employed to study the polypeptide chains after resolution by analytical polyacrylamide gel electrophoresis. The protein eluted from the capsid region of the polyacrylamide gel (peak I, II, see Fig. 2) formed two distinct precipitin lines with the rabbit antiserum prepared against highly purified SDS dissociated SV40 virus particles (Fig. 8b). The antiserum did not form a precipitin line with extracts of uninfected monkey kidney cells. A single precipitin line somewhat weaker was also observed with the protein eluted from peak III (cf. Fig. 2). No precipitin lines were observed with protein eluted from the nucleocapsid region and other minor bands with this antiserum.

\section{DISCUSSION}

The virus selected for this study was the stable small-plaque type of SV40 which can replicate in several AGMK cell lines (CV-1, Vero, and BSC-1). It is capable of transforming hamster cells in vitro and inducing the formation of transplantable tumors in vivo. Previous studies on the structural proteins of SV40 have employed the large-plaque mutant which has been shown to have a reduced efficiency in inducing $\mathrm{T}$ antigen and transformation (21).

The results of this study have shown that at least four polypeptides can be separated by analytical polyacrylamide gel electrophoresis from solubilized highly purified mature SV40 virus particles. The major component of the virion is the capsid component of approximately 45,000 to 50,000 molecular weight. On the basis of radio- activity, the capsid protein was estimated to represent 75 to $80 \%$ of the total protein of the mature virion.

The capsid protein appears to contain two polypeptide chains from staining patterns observed after gel electrophoresis. It has not been possible to completely separate the capsid subunits by the usual methods of analytical polyacrylamide gel electrophoresis in SDS or $8 \mathrm{~m}$ urea after dissociation of the protein in SDS, urea, or guandine hydrochloride and with reduction and alkylation of the polypeptide chains. Additional evidence that the capsid protein contains two polypeptides was obtained from the immunological and isoelectric focusing studies. It is of particular interest that the capsid subunits retained immunological reactivity to form two distinct precipitin lines by the agar immunodiffusion technique after treatment with SDS, ME, and separation by electrophoresis, in neutral SDS polyacrylamide gels.

The electrofocusing procedure which separates proteins according to their isoelectric points in a stable $p \mathrm{H}$ gradient appears to possess a higher resolving power than most electrophoretic techniques based on molecular size and charge at a fixed $p \mathrm{H}$. The results that we obtained by the isoelectric fractionation procedure further support the conclusion that the capsid proteins contain two subunits with $p \mathrm{H}$ optima of 5.5 and 6.4. It will be of interest to utilize the isoelectric fractionation procedure to completely separate the capsid subunits and obtain molecular weight determinations and to further characterize these major structural viral proteins. It should be noted here that Anderer et al. (1) originally suggested
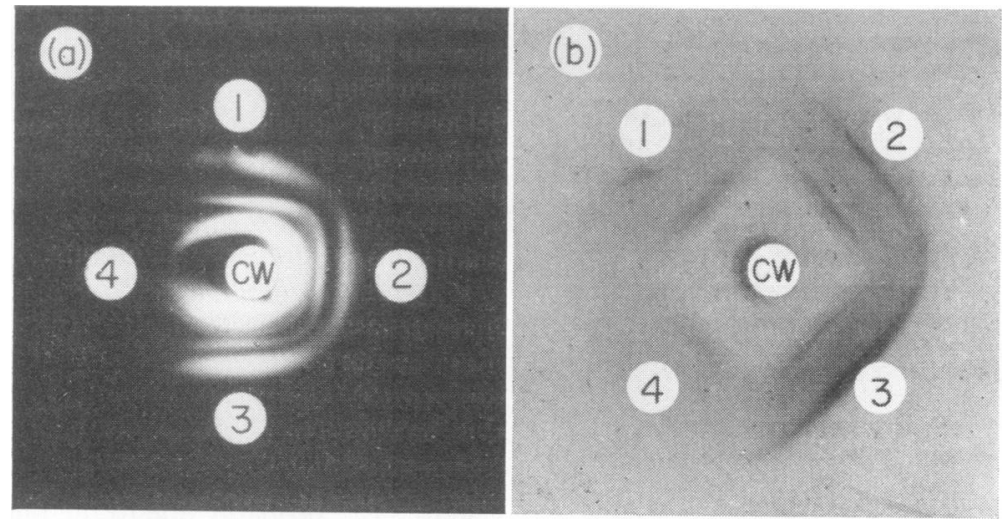

FIG. 8. Immunodiffusion analyses of solubilized SV40 whole virions and capsid proteins. The center wells contained antisera against sodium dodecyl sulfate (SDS) dissociated SV40 virions. (a) The outer wells, 1 to 3 , contain different preparations of SDS dissociated SV40 virus particles; well 4 contains an SDS extract of uninfected Vero cells. (b) The outer wells contain protein eluted from successive gel slices of the capsid region after electrophoresis. After SDS gel electrophoresis of the dissociated virions, the gel was frozen, cut into fractions $1.3 \mathrm{~mm}$ wide, and crushed in vials with a glass rod. The capsid proteins were eluted overnight with $0.1 \mathrm{ml}$ buffered saline at $4 C$. A parallel stained gel was employed to locate the capsid region. 
that the SV40 capsid protein contained two similar polypeptides of approximately 16,350 molecular weight of the dimer of 35,800 . The reason for the differences in molecular weight results is not yet clear. The molecular weight of the whole capsid protein determined in this study agrees with that reported recently by Girard et al. (5).

Of the two minor structural protein components separated by gel electrophoresis, peak IV is associated with viral DNA in a nucleoprotein core, makes up approximately 7 to $9 \%$ of the virion protein, and has an estimated molecular weight of 16,000 daltons. Lack of immunological reactivity of the core protein may be attributable to the low concentration in the virion, or alternatively it may have been destroyed by the SDS solubilization.

The other minor electrophoretically separated protein component, peak III, has an estimated molecular weight of 29,000 and was immunologically reactive. The location of this peptide in the architecture of the virion is not known at this time.

\section{ACKNOWLEDGMENTS}

We wish to thank Bernard Moss for helpful suggestions and gratefully ack nowledge the excellent technical assistance of Henry O. Schulze.

\section{LITERATURE CITED}

1. Anderer, F. A., H. D. Schlumberger, M. A. Koch, H. Frank and H. J. Eggers. 1967. Structure of simian virus 40. II. Symmetry and components of the virus particle. Virology 32:511-523.

2. Anderer, F. A., M. A. Koch, and H. D. Schlumberger. 1968. Structure of simian virus 40. III. Alkaline degradation of the virus particle. Virology 34:452-458.

3. Black, P. H., W. P. Rowe, H. C. Turner, and R. J. Huebner 1963. A specific complement-fixing antigen present in SV40 tumor and transformed cells. Proc. Nat. Acad. Sci. U.S.A. 50: 1148-1156.

4. Crawford, L. V., and P. H. Black. 1964. The purification of simian virus 40 . Virology 24:381-387.

5. Girard, M., L. Marty, and F. Suarez. 1970. Capsid proteins of simian virus 40. Biochem. Biophys. Res. Commun. 40:97102.

6. Habel, H., and B. E. Eddy. 1963. Specificity of resistance to tumor challenge of polyoma and SV40 virus-immune hamsters. Proc. Soc. Exp. Biol. Med. 113:1-12.

7. Hirs, C. H. W. 1967. Reduction and S-carboxymethylation of proteins, p. 199-203. In Methods in enzymology, vol. XI. Academic Press Inc., N.Y.

8. Horowitz, M. S., and M. D. Scharff. 1967. The production of antiserum against viral antigens. In $\mathrm{K}$. Habel and $\mathbf{N}$. P. Salzman (ed.), Fundamental techniques in virology. Academic Press Inc., N.Y.

9. Kit, S., D. R. Dubbs, P. Frearson, and J. Melnick. 1966. Enzyme induction in SV40-infected Green monkey kidney cultures. Virology 29:69-83.

10. Kit, S., L. J. Piekarski, and D. R. Dubbs. 1967. DNA polymerase induced by simian virus 40 . J. Gen. Virol. 1:163173.

11. Koch, M. A., H. J. Eggers, F. A. Anderer, H. D. Schlumberger, and H. Frank. 1967. Structure of simian virus 40. I. Purification and physical characterization of the virus particle. Virology 32:503-510.

12. Lowry, O. H., N. J. Rosebrough, A. L. Farr, and R. J. Randall. 1951. Protein measurement with the Folin phenol reagent. J. Biol. Chem. 193:265-275.

13. Maizel, J. V., Jr., D. O. White, and M. D. Scharff. 1968. The polypeptides of adenovirus. I. Evidence for multiple protein components in the virion and a comparison of types $2,7 \mathrm{~A}$, and 12. Virology 36:115-125.

14. Moss, B., and N. P. Salzman. 1968. Sequential protein synthesis following vaccinia virus infection. J. Virol. 2:10161027.

15. Salzman, N. P., and B. Moss. 1969. Analysis of radioactively labeled proteins by immunodiffusion. In Fundamental techniques in virology. Academic Press Inc., New York.

16. Schlumberger, H. D., F. A. Anderer, and M. A. Koch. 1968 Structure of simian virus 40 . IV. The polypeptide chains of the virus particle. Virology 36:42-47.

17. Shapiro, A. L., E. Vinuela, and J. V. Maizel. 1967. Molecular weight estimation of polypeptide chains by electrophoresis in SDS polyacrylamide gels. Biochem. Biophys. Res. Commun. 28:815-820.

18. Summers, D. F., J. V. Maizel, and J. E. Darnell, Jr. 1965. Evidence for virus-specific noncapsid proteins in poliovirusinfected HeLa cells. Proc. Nat. Acad. Sci. U.S.A. 54:505513.

19. Tevethia, S. S., G. T. Diamandopoulos, F. Rapp, and J. F. Enders. 1968. Lack of relationship between virus-specific surface and transplantation antigens in hamster cells transformed by simian papovavirus SV40. J. Immunol. 101:11921198.

20. Tevethia, S. S., M. Katz, and F. Rapp. 1965. New surface antigen in cells transformed by simian papovavirus SV40. Proc. Soc. Exp. Biol. Med. 119:896-901.

21. Todaro, G. J. and K. K. Takemoto. 1969. Rescued SV40: increased transforming efficiency in mouse and human cells. Proc. Nat. Acad. Sci. 62:1031-1037.

22. Vesterberg, O., and H. Svensson. 1966. Isoelectric fractionation, analysis, and characterization of ampholytes in natural pH gradients. Acta Chem. Scand. 20:820-834. 